\title{
AC 2007-2701: APPLIED COMPUTER AIDED DESIGN USING AEROSPACE VEHICLES FOR SOPHOMORE LEVEL STUDENTS
}

\section{James Helbling, Embry-Riddle Aeronautical University}

Currently an Assistant Professor of Aerospace Engineering where he teaches structural analysis, computer aided design, and aircraft detail design courses. He has 21 years of industry experience with McDonnell Douglas (now Boeing) and Northrop Grumman Corporation where he specialized in structural fatigue loading and served as manager of F-5/T-38 Engineering.

\section{Darin Marriott, Embry-Riddle Aeronautical University}

Dr. Marriott is currently an Assistant Professor of Aerospace Engineering at Embry Riddle Aeronautical University. He teaches space propulsion systems, experimental space systems and computer aided design. His graduate research focused on plasma dynamics for space propulsion and his current research involves creation of linear induction catapults for researching high speed launch applications.

\section{Thomas Gally, Embry-Riddle Aeronautical University}

Currently Chair and Associate Professor of Aerospace Engineering specializing in teaching aerodynamics and aircraft design. He has industry experience with Boeing Commercial Airplanes-Seattle, General Dynamics Fort Worth Division, and NASA's Langley Research Center and Johnson Space Center; prior academic experience with the American University in Cairo and Texas A\&M University. 


\title{
Applied Computer Aided Design Using Aerospace Vehicles for Sophomore Level Students
}

\author{
Jim Helbling, Darin Marriott, and Tom Gally \\ Aerospace Engineering \\ Embry-Riddle Aeronautical University-Prescott
}

\section{Introduction}

The Aerospace Engineering Department at Embry-Riddle Aeronautical University-Prescott recently revised its basic Computer Aided Design (CAD) course to include a significant aerospace vehicle design component. The purpose of this course is intended to both introduce the students to engineering design graphics using modern CAD tools and to bridge the gap between a freshmen course in the introduction to design and the senior capstone design courses. Also, the positioning of this course in the sophomore year allows for the use of more advanced concepts than can realistically be expected for freshman while providing an introduction to the concepts and analysis methods the students will learn as juniors. The use of CAD tools in the design reinforces the computer skills the students need later, particularly in capstone design, and provides a motivation for our students who are excited by aerospace vehicles.

The content of the course provides for a parallel development of CAD skills with the introduction of aerospace vehicle concepts and analysis tools. The course includes an experience in both spacecraft design (astronautics) and aircraft design (aeronautics) in line with the degree options the students will have during the following two years. The introduction of part and assembly design methods facilitates the spacecraft design which, by and large, consists of simple geometric shapes. The introduction of complex shapes and surface lofts later in the semester facilitates the design of aircraft which typically have more complex geometries due to aerodynamic shaping.

The first semester of offering this course appears to have been a great success in both achieving the desired academic outcomes and in creating fun and excitement in an otherwise very intense sophomore year. The follow sections describe in more detail the goals and implementation of this course as well as some lessons learned after the first semester.

\section{Course Creation and Implementation}

The impetus for creating the Computer Aided Conceptual Design course was twofold: 1) to create a sophomore level design course to get students excited about aerospace engineering, and 2) to provide more timely instruction of Computer Aided Design (CAD) and show how it relates to the design of an aerospace system. A recent engineering curriculum change at Embry-Riddle resulted in the creation of a 'common freshmen experience', where students are introduced to an interdisciplinary curriculum consisting of aerospace, electrical, and computer engineering courses. As a result of this change, Aerospace Engineering students were no longer being exposed to aircraft or spacecraft design during their first two years of study. The Computer Aided Conceptual Design course is meant to address this gap, and thereby provide a preview of 
the type of course content presented to upperclassmen. A byproduct of this curriculum change is expected to be an increase in $\mathrm{AE}$ student retention.

A portion of the current course content is a carry-over from the previous CAD course. It was felt that it was important to continue to offer instruction in proper methods for creating drawings, so standards and conventions for creating orthographic views and applying dimensions are covered in detail. Nonstandard views (i.e. isometric, section, and auxiliary views) and proper methods for creating part and assembly drawings are also explained in a similar manner to what they were in the previous course. The primary change in course content involves the additional instruction geared specifically toward the design of an aircraft or spacecraft. The focus of this instruction is left to the discretion of the instructor, as is described in more detail in the following section. Each course section is required to include some content in both aircraft and spacecraft design, however.

To assist students in creating CAD models representative of their designs, tutorials have been created showing step-by-step illustrated instructions providing the methods required for creating aircraft or spacecraft components. In one of the course sections, this effort culminates in the creation of a wind tunnel model assembly which is created using a 3 dimensional printer rapid prototyping system. Student design teams assemble the plastic components generated by the printer, and install them in our 32" by 45 " closed return low speed wind tunnel. The teams then perform flow visualization testing to identify areas of laminar and turbulent flow on their models.

The implementation of this course is intended to improve ERAU students' preparation for their capstone courses and better meet the student Outcomes and Objectives defined by the College of Engineering in accordance with ABET requirements. In particular, the new course allows students to gain additional depth in theoretical, computational, and experimental methods (Objective IV B) and allows students to be more laboratory and computer proficient while using modern equipment and current computer methods (Outcome 8). In addition, the students utilize appropriate design software (Objective I B), better understand the importance of teamwork (Objective III B), and are introduced to design processes (Outcome 6).

The execution of this course requires the instructor to provide both CAD instruction and lessons on proper methodology related to aerospace design. The varying methods used during the first semester that the course was offered are recounted in the following section.

\section{Contrasts in Teaching Methods}

As a 3 credit hour course per semester, there are 42 class meeting times for 2 hours each - the $2^{\text {nd }}$ hour is normally left open for in class work time on projects or homework. All course sections offered included a basic portion which was based upon the successful predecessor to this course which focused on CAD only. This common portion of 28 class meetings consists of:

- 3 Lectures on Design, Design Philosophies and Design for Manufacturing

- 19 Lectures on Drafting principles and using CATIA. This includes two days focused on layout a wing and fuselage - time closely associate with the aircraft projects.

- 3 Exam Days 
- 2 Working Days on semester projects

- 1 Presentation Day for semester projects

The extension of the include Aerospace Vehicle Design (and extending the course to 3 credits) allowed 14 extra class days to be utilized.

- 10 Lectures on vehicle concepts, systems and design methods.

- 3 Additional Workdays on semester projects.

- 1 Additional Project Presentation Day

How these additional days were utilized depended strongly on the background and approach used by the different instructors. On one extreme was assigning the bulk of the time to the discussion of aircraft analysis/design based upon a traditional course textbook ${ }^{1}$. On the other, the time was split roughly 50/50 between spacecraft design and aircraft design with the use of courses texts and online material as references ${ }^{1-3}$.

The goal of all instructors was to provide an introductory knowledge to students on the varying aspects of aerospace vehicle design to both provide an exciting context for learning CAD as well as to motivate the material to be learned in later courses on specific topics.

The major challenge in using complete vehicle design in the sophomore design is the determination of the correct balance between introducing conceptual ideas, analysis methods and design approaches. As a contrast, teaching senior capstone design - which two of the three instructors have or are also currently teaching - can emphasis design very strongly while highlighting the application of concepts and analysis methods learned in pre-requisite courses. Sophomores have weak conceptual background, often informally acquired, and only a budding knowledge of analysis and, as a result, their approach to design is often haphazard and nonrigorous. Another goal is thus to provide sufficient substantive material to motivate a rigorous design, compatible with the students existing capabilities, while focusing on the design decision making and creativity.

\section{Lessons Learned}

The feedback received for the section that concentrated primarily on aircraft design was very positive. Students indicated that they enjoyed applying aerodynamic theory in conceptualizing improvements to existing aircraft. They also thoroughly enjoyed creating physical models from CAD models through the use of the 3 dimensional printers and then seeing their models installed in the wind tunnel for flow visualization testing. (Several students even took their models home with them during the break between semesters so they could show them off to their families and friends.) However, the planned use of 'canned' software to allow students to perform quick design trade studies was abandoned in favor of a 'handout' which provided students with the option of choosing several assumptions to facilitate completion of their project before the end of the semester. Use of these assumptions made the analysis performed less than rigorous, although it did provide a preview of the more complete analysis to be required of students in senior capstone courses. The project was also highly end-loaded, with a large amount of work required of the design teams at the end of the semester. An attempt will be made in the future to provide 
teams with more of the required analysis tools earlier in the semester to help spread the workload more evenly and potentially allow for a more complete analysis of their design options.

\section{Bibliography}

1) Brandt, S. A., Stiles, R. J., Bertin, J. J., Whitford, R, Introduction to Aeronautics: A Design Perspective, $2^{\text {nd }} E d .$, AIAA, 2004.

2) Sellers, J. J., Understanding Space: An Introduction to Aeronautics, $3^{\text {rd }}$ Ed., McGraw-Hill, 2005.

3) Texas Space Grant Consortium (TSGC) Spacecraft Design website, http://www.tsgc.utexas.edu/archive/index.html 